\title{
Comparative cytogenetic mapping of three genes involved in sex determination in four species of the family Canidae*
}

\author{
J. Nowacka-Woszuk and M. Switonski ${ }^{1}$ \\ Poznań University of Life Sciences, Department of Genetics and Animal Breeding, \\ Faculty of Animal Breeding and Biology \\ Wotyńska 33, 60-637 Poznań, Poland
}

(Received 25 May 2009; revised version 27 October 2009; accepted 29 January 2010)

\begin{abstract}
Advanced knowledge of the canine genome facilitates progress in studies on genome maps of other canids, including species considered also as farm animals. In this study canine BAC (Bacterial Artificial Chromosome) probes, harbouring three genes involved in sex determination ( $S O X 9$ - sex determining region Y- box 9, $A M H$ - anti-Müllerian hormone and $A R$ - androgen receptor), were mapped in the dog, red fox, arctic fox and Chinese raccoon dog chromosomes. Localization of these genes can be helpful in association studies focused on monogenetic intersexual disorders.
\end{abstract}

KEY WORDS: Canidae, cytogenetic mapping, $S O X 9, A M H, A R$

\section{INTRODUCTION}

The family Canidae consists of 36 species, including the dog (Canis lupus f. familiaris), red fox (Vulpes vulpes), arctic fox (Alopex lagopus) and Chinese raccoon dog (Nyctereutes procyonides). Karyotypes of these species differ significantly from each other and their evolution has been extensively studied (Switonski et al., 2003; Graphodatsky et al., 2008). Foxes and Chinese raccoon dogs are also kept in captivity on fur farms.

Genome organization of these species has been extensively studied and the

\footnotetext{
* Supported by the Polish Ministry of Science and Higher Education, Grant No. N301 111 31/3332

${ }^{1}$ Corresponding author: e-mail: switonsk@jay.au.poznan.pl
} 
most advanced knowledge concerns the dog (Breen, 2008). Comparative analysis of genome organization in the family Canidae was mainly carried out using the socalled comparative chromosome painting (Graphodatsky et al., 2008). In addition, comparative analyses were conducted by mapping of DNA microsatellite markers or genes in chromosomes of the red fox, arctic fox and Chinese raccoon dog, but the number of the FISH mapped loci is still very low (Switonski et al., 2009).

Sex determination is controlled by dozens of genes (Wilhelm et al., 2007) and among them a crucial role in maleness determination, apart from the $S R Y$ (sex determining region $\mathrm{Y}$ ), is played by the $S O X 9$ (sex determining region $\mathrm{Y}$ - box 9), $A M H$ (anti-Müllerian hormone or MIS - Müllerian-Inhibiting Substance) and $A R$ (androgen receptor) genes. It is commonly known that mutations of these genes may cause intersexuality in pet species (Lyle, 2007) as well as in other mammals. In spite of the fact that the intersexual phenotype is quite often reported in the dog, to date only one causative mutation has been described (Wu et al., 2009). In this report chromosomal localization of three genes (SOX9, AMH and $A R$ ) in four canids is presented.

\section{MATERIAL AND METHODS}

Chromosome preparations were obtained from in vitro cultured lymphocytes. The slides were Q-banded with quinacrine prior to fluorescence in situ hybridization (FISH). The BAC clones were selected based on the comparative analysis of the nucleotide number localization of studied genes deposited in the GenBank contigs and sequences of inserts contained in particular BAC clones (http://genome.ucsc. edu/cgi-bin/hgGateway). The selected clones originated from the canine genomic bacterial artificial chromosome (BAC) library (http://bacpac.chori.org/). For the SOX9, AMH and AR genes clones numbered CH82-137H10, CH82-136N17 and CH82-139H19, respectively, were selected. Each clone was verified by PCR to contain the studied gene. The sequence of PCR primers and reaction details are shown in Table 1.

The probes used in FISH experiments were labeled by random priming with biotin-16dUTP using Prime-It Fluor Fluorescence Labeling Kit (Stratagene). The avidin-FITC and anti-avidin system for hybridization signal detection was applied. Chromosome slides were DAPI stained and the international chromosome nomenclature of the dog (Switonski et al., 1996), red fox (Committee for the Standard Karyotype of Vulpes fulvus Desm., 1985), arctic fox (Committee for the Standard Karyotype of Alopex lagous L., 1985) and Chinese raccoon dog (Pienkowska et al., 2002) were applied. Slides were analysed under a fluorescence microscope (Nikon E600 Eclipse) equipped with a cooled digital CCD camera and Lucia software. 
Table 1. The sequence of primers and PCR conditions used for BAC clone verification

\begin{tabular}{|c|c|c|c|c|c|}
\hline Gene & $\begin{array}{r}\text { Amplified } \\
\text { fragment }\end{array}$ & $\begin{array}{c}\text { GenBank } \\
\text { accession } \\
\text { no. }\end{array}$ & Sequence of primer pairs & $\begin{array}{l}\text { Product } \\
\text { size }\end{array}$ & $\begin{array}{l}\text { Annealing } \\
\text { temp. }\end{array}$ \\
\hline SOX9 & exon 3 & AY237827 & $\begin{array}{l}\text { F: 5' TCCCGCACTACAGCCCGTCCTACC } \\
\text { R: 5' AGTGCTGGGGGCTGTGCGTCTGC }\end{array}$ & 219 bp & $68^{\circ} \mathrm{C}$ \\
\hline$A M H$ & exon 1 & XM542190 & $\begin{array}{l}\text { F: 5' CGAGGCCCCCGGAGGTGAGGTC } \\
\text { R: 5' CCCCGAAGGTGGCCAGGTCGTG }\end{array}$ & $266 \mathrm{bp}$ & $65^{\circ} \mathrm{C}$ \\
\hline$A R$ & exon 6 & AF197950 & $\begin{array}{l}\text { F: 5' GGGAGGGCAACCAAAGACATTCT } \\
\text { R: 5' TTCCCCTTTGAGTGCCTATGACCT }\end{array}$ & $279 \mathrm{bp}$ & $65^{\circ} \mathrm{C}$ \\
\hline
\end{tabular}

\section{RESULTS}

The applied canine BAC probes gave hybridization signals on a single chromosome pair in the dog (CFA), red fox (VVU), arctic fox (ALA) and Chinese raccoon dog (NPP) (Figure 1). The SOX9 gene was assigned to CFA9q11, VVU2p24 (Figure 2), ALA12q22-23 and NPP5q16-17. The $A M H$ gene was localized in CFA20q16-17, VVU9q16, ALA7p13 and NPP25q14. The X-linked $A R$ gene was assigned to this chromosome close to the centromere and in three species (the dog and the foxes) the hybridization signal was found in the first band of the long arm (Xq11), while in the raccoon dog it was localized in NPPXq11-12.

\section{DISCUSSION}

The great phenotypic variability of dog breeds (with over 400 breeds existing) and the occurrence of hereditary diseases similar to human ones have made the dog an interesting animal model for molecular studies of these diseases, including gene therapy. Thus, extensive studies of the dog genome organization and finally its sequencing have been undertaken.

The chromosome comparative painting, with regard to the dog, red fox and arctic fox genomes, was performed by Graphodatsky et al. $(2000,2008)$. Altogether, 42 highly conserved segments in these species were identified. It was shown that CFA9, harbouring the SOX9 locus, corresponds to the $2 \mathrm{p}$ arm of the red fox (VVU2p) and the 12q arm of the arctic fox (ALA12q). In turn, the dog chromosome 20 (CFA20), where the $A M H$ gene is located, is an ortholog of the red fox chromosome 9q arm (VVU9q) and the arctic fox chromosome $7 \mathrm{p}$ arm (ALA7p). A similar approach for the dog and Chinese raccoon dog genomes was adopted by Nie et al. (2003). From that study it is known that dog 
chromosome 9 (CFA9) corresponds to the long arm of chromosome 5 of the Chinese raccoon dog (NPP5q), while chromosome 20 (CFA20) is an ortholog of NPP25. Since it is commonly known that the organization of the X chromosome is highly conserved in mammals, it was not surprising that the location of the $A R$ gene was very similar in the studied species - in the vicinity of the centromere in the long arm. Our results are in agreement with the painting data, since all localizations were found in the predicted chromosome arms (Figure 1). However, the location of the $S O X 9$ gene appeared to be exceptional, since in the canine chromosome 9 its locus was found proximally (close to the centromere), while in the other studied canids it was in the distal position (close to the telomere). It is assumed that during genome evolution a whole arm inversion event took

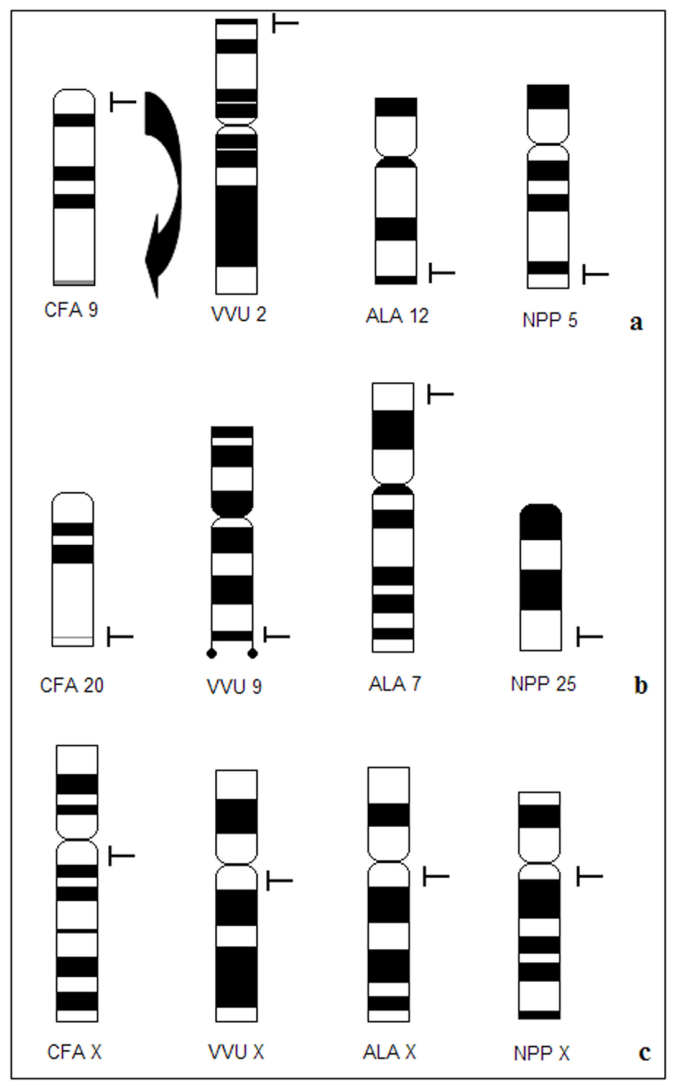

Figure 1. Diagrammatic representation of chromosomal location of the $S O X 9$ (a), $A M H$ (b) and $A R$ (c) genes in the studied species (chromosome symbols referred to the dog - CFA; red fox - VVU; arctic fox - ALA and Chinese raccoon dog - NPP) 


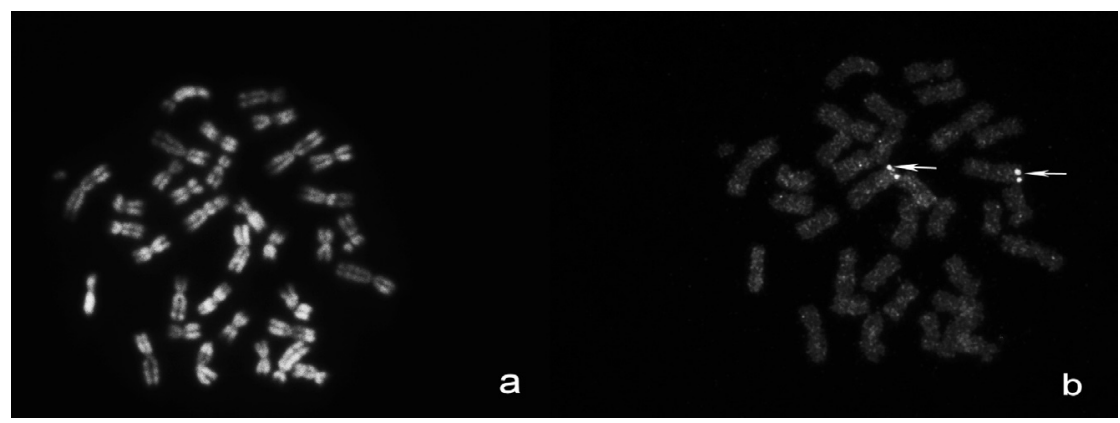

Figure 2. Location of the $S O X 9$ gene in the red fox chromosomes - VVU2p24: a. Q-banding prior to FISH; b. the same metaphase after FISH

place. Similar cases of centromeric-telomeric inversions were previously described in this family. For instance, the ATP2A gene locus is near the centromere in the dog (CFA26q), while in other canids this locus is in the telomeric region of the VVU10p, ALA14q and NPP19q chromosome arms. In general, until now an inverted organization of chromosome arms was described by localization of the locus-specific probes for the dog chromosomes: 7, 9, 16, 17, 18, 19, 22, 26, 29 and 34 (for details see Szczerbal et al., 2006).

Knowledge on monogenetic hereditary diseases in the dog is quite advanced (http://www.ncbi.nlm.nih.gov/sites/entrez?db=omia\&tool=toolbar); however, only one gene mutation responsible for the intersexual syndrome was identified (Wu et al., 2009). In the reference family (Miniature Schnauzer $\times$ Beagle), where the Persistent Müllerian Duct Syndrome (PMDS) was identified, the causative mutation in an a priori selected candidate gene (MISRII) was searched for. Sequencing of the coding region of this gene revealed a single nucleotide substitution (C241T) in exon 3. This mutation caused the occurrence of the STOP codon and in consequence the polypeptide was shortened (80 amino acids instead of 602). The PMDS was also diagnosed in the Miniature Schnauzer breed. Vegter et al. (2008) analysed a male dog with unilateral cryptorchidism and signs of feminization. The analysis revealed the presence of an enlarged testis with the Sertoli cell tumor and inactive germ cells. Moreover the uterus and uterine horn-like structures were present. Another case in this breed was described by Matsuu et al. (2009) in a dog with male external genitalia and bilateral cryptorchidism. Histological analysis revealed the Sertoli cell tumor and a normal uterus. The cytogenetic analysis confirmed the male karyotype $(78, \mathrm{XY})$, while the molecular test showed the presence of the $S R Y$ gene. In neither case were molecular studies of the candidate genes ( $A M H$ or $A M H R$ ) undertaken. The PMDS was also recently diagnosed in a phenotypically female (English cocker spaniel) dog with ambiguous external genitalia (Whyte 
et al., 2009). Laparoscopy examination revealed two testicles without germ cells, abnormally developed epididymides and uterus with horns. Moreover, the endocrinological test showed an increase of serum progesterone concentration. The male karyotype and the presence of the $S R Y$ gene were confirmed. Similarly to previous cases, no molecular analysis of candidate genes was performed. Another case of male pseudohermaphroditism was described in a phenotypically female (Dachshund) with an enlarged clitoris (Nowacka-Woszuk et al., 2007). This intersex presented male behaviour and clinical examination revealed the presence of abdominal gonads resembling testes. Cytogenetic evaluation showed a normal male karyotype and molecular analysis of the coding sequence of the $S R Y$ and $S O X 9$ genes did not reveal any mutation.

The androgen insensitivity syndrome, caused by a mutation of the $A R$ gene, is a well-known intersexual phenotype in mammals, including human (http:// androgendb.mcgill.ca/). However, in dogs only few tentative cases were reported to date. Peter et al. (1993) described a male dog $(78, \mathrm{XY})$ with testicle hypoplasia. The analysis of an in vitro cultured fibroblast, originating from gonads of this animal, showed a lack of dihydrotestosterone affinity to the tested tissue. Unfortunately, the sequence of the $A R$ gene was not studied.

Among intersexual syndromes the most frequent one in dogs is sex reversal in animals with a female karyotype (78,XX; $S R Y$-negative). Several genes were tested in reference families by segregation analysis of microsatellite markers localized in the vicinity of the candidate genes (Kothapalli et al., 2005). However, none of the considered genes was confirmed as the candidate. This approach showed that knowledge on the location of genes involved in sex determination in farm furbearing canids can potentially be useful in similar studies.

It may be expected that also in other canids intersexual syndromes are not rare, in spite of the fact that only two reports concerning the Chinese raccoon dog were published. One case was classified as the androgen insensitivity syndrome by Smith et al. (1983) and the other was a case of male pseudohermaphroditism (Weng et al., 2005). Neither case was studied in terms of molecular genetics.

\section{CONCLUSIONS}

Localization of analysed genes in chromosomes of the red fox, arctic fox and Chinese raccoon dog enlarged, still very poor, physical maps of these species. Moreover, this data can be helpful in association studies focused on monogenetic intersexual disorders. 


\section{REFERENCES}

Breen M., 2008. Canine cytogenetics--from band to basepair. Cytogenet. Genome Res. 120, 50-60

Committee for the Standard Karyotype of Alopex Lagopus L. (A. Makinen, co-ordinator), 1985. The standard karyotype of the blue fox (Alopex lagopus L.). Hereditas 103, 33-38

Committee for the Standard Karyotype of Vulpes Fulvus Desm. (A. Makinen, co-ordinator), 1985. The standard karyotype of the silver for (Vulpes fulvus Desm.). Hereditas 103, 171-176

Graphodatsky A.S., Perelman P.L., Sokolovskaya N.V. et al., 2008. Phylogenomics of the dog and fox family (Canidae, Carnivora) revealed by chromosome painting. Chromosome Res. 16, 129-143

Graphodatsky A.S., Yang F., O‘Brien P.C., Serdukova N., Milne B.S., Trifonov V., Ferguson-Smith M.A., 2000. A comparative chromosome map of the arctic fox, red fox and dog defined by chromosome painting and high resolution G-banding. Chromosome Res. 8, 253-263

Kothapalli K., Kirkness E., Pujar S., Van Wormer R., Meyers-Wallen V.N., 2005. Exclusion of candidate genes for canine SRY-negative XX sex reversal. J. Hered. 96, 759-763

Lyle S.K., 2007. Disorders of sexual development in the dog and cat. Theriogenology 68, 338-343

Matsuu A., Hashizume T., Kanda T., Nagano M., Sugiyama A., Okamoto Y., Hikasa Y., 2009. A case of Persistent Müllerian duct syndrome with Sertoli cell tumor and hydrometra in a dog. J. Vet. Med. Sci. 71, 379-381

Nie W., Wang J., Perelman P., Graphodatsky A.S., Yang F., 2003. Comparative chromosome painting defines the karyotypic relationships among the domestic dog, Chinese raccoon dog and Japanese raccoon dog. Chromosome Res. 11, 735-740

Nowacka-Woszuk J., Nizanski W., Klimowicz M., Switonski M., 2007. Normal male chromosome complement and a lack of the SRY and SOX9 gene mutations in a male pseudohermaphrodite dog. Anim. Reprod. Sci. 98, 371-376

Peter A.T., Markwelder D., Asem E.K.,1993. Phenotypic feminization in a genetic male dog caused by nonfunctional androgen receptors. Theriogenology 40, 1093-1105

Pienkowska A., Szczerbal I., Mäkinen A., Switonski M., 2002. G/Q-banded chromosome nomenclature of the Chinese raccoon dog, Nyctereutes procyonoides procyonoides Gray. Hereditas 137, 75-78

Smith A., Nes N., Berg K.A., Valtonen M., Mäkinen A., Lukola A., 1983. Testicular feminization in the Finnish racoon dog (Nyctereutes procyonoides). Nord Vet. Med. 35, 452-459

Switonski M., Reimann N., Bosma A.A., Long S., Bartnitzke S., Pienkowska A., Moreno-Milan M.M., Fischer P., 1996. Report on the progress of standardization of the G-banded canine (Canis familiaris) karyotype. Committee for the Standardized Karyotype of the Dog (Canis familiaris). Chromosome Res. 4, 306-309

Switonski M., Rogalska-Niznik N., Szczerbal I., Baer M., 2003. Chromosome polymorphism and karyotype evolution of four canids: the dog, red fox, arctic fox and raccoon dog. Caryologia 56, 375-385

Switonski M., Szczerbal I., Nowacka-Woszuk J., 2009. Comparative genomics of 3 farm canids in relation to the dog. Cytogenet. Genome Res. 126, 86-96

Szczerbal I., Klukowska-Roetzler J., Dolf G., Schelling C., Switonski M., 2006. FISH mapping of 10 canine BAC clones harbouring genes and microsatellites in the arctic fox and the Chinese raccoon dog genomes. J. Anim. Breed. Genet. 123, 337-342

Vegter A.R., Kooistra H.S., van Sluijs F.J., van Bruggen L.W., Ijzer J., Zijlstra C., Okkens A.C., 2010. Persistent Mullerian Duct Syndrome in a Miniature Schnauzer dog with signs of feminization and a Sertoli cell tumour. Reprod. Domest. Anim. doi: 10.1111/j.1439-0531.2008.01223.x (in press) 
Weng Q., Murase T., Asano M., Tsubota T., 2005. Male pseudohermaphroditism in a raccoon dog (Nyctereutes procynoides). J. Vet. Med. Sci. 67, 603-605

Whyte A., Monteagudo L.V., Díaz-Otero A., Lebrero M.E., Tejedor M.T., Falceto M.V., Whyte J., Gallego M., 2009. Malformations of the epididymis, incomplete regression of the mesonephric tubules and hyperplasia of Leydig cells in canine persistence of Müllerian duct syndrome. Anim. Reprod. Sci. 115, 328-333

Wilhelm D., Palmer S., Koopman P., 2007. Sex determination and gonadal development in mammals. Physiol. Rev. 87, 1-28

Wu X., Wan S., Pujar S., Haskins M.E., Schlafer D.H., Lee M.M., Meyers-Wallen V.N., 2009. A single base pair mutation encoding a premature stop codon in the MIS type II receptor is responsible for canine persistent Müllerian duct syndrome. J. Andrology 30, 46-56 